\title{
Percepção dos Estudantes de Medicina sobre Comunicação de Más Notícias na Formação Médica
}

\section{PALAVRAS-CHAVE \\ - Educação Médica. \\ - Aprendizagem Baseada em Problemas. \\ - Comunicação em Saúde. \\ - Relações Médico-Paciente. \\ - Humanização da Assistência.}

\section{The Perception of Medical Students about Communication of Bad News in Medical Education}

Natália Caroline Dias ${ }^{I \odot}$ Danielle Abdel Massih Pio ${ }^{I \odot}$

\begin{abstract}
RESUMO
Introdução: A comunicação se apresenta como uma habilidade que deve ser conquistada na graduação médica, configurando-se como um campo de conhecimento a ser contemplado no que se refere à formação médica. A forma como a comunicação é feita, incluindo seu conteúdo, constitui um importante elemento do vínculo estabelecido entre paciente, equipe, família e instituição de saúde. Diante das Diretrizes Curriculares Nacionais, estimula-se a aprendizagem por meio de metodologias ativas, com a comunicação como parte do processo ensino-aprendizagem, com o desafio de contemplar a comunicação de más notícias de forma efetiva na formação. Objetivo: Analisar as percepções de estudantes de Medicina que cursam um currículo organizado com metodologias ativas acerca da comunicação de más notícias na formação. Método: Tratou-se de um estudo qualitativo, realizado na Faculdade de Medicina de Marília (SP). Participaram da pesquisa 39 estudantes da primeira à sexta série do curso de Medicina. A coleta de dados foi realizada por meio de entrevista semiestruturada, e os dados foram analisados por meio da técnica de Análise de Conteúdo, na modalidade temática. Resultados e discussão: Com base na análise realizada, foram identificadas quatro categorias temáticas: Dificuldades em definir "comunicação de más notícias": produto ou processo?; É possível aprender a dar ou receber más notícias pela experiência?; Dificuldades na implementação do currículo integrado: insuficiente articulação teórico-prática em comunicação de más notícias; Valorizando a comunicação de más notícias: é preciso preparo teórico, técnico e emocional. Os resultados permitem um olhar circunscrito e importante da percepção dos estudantes sobre a comunicação de más notícias dentro da proposta curricular. Considerações finais: Aponta-se que os participantes do estudo percebem a necessidade de maior articulação teórico-prática, preparo dos docentes e um cuidado com a formação pessoal e profissional dos estudantes acerca do que abrange a comunicação de más notícias. Espera-se que o estudo contribua para ampliação dos olhares acerca do tema no que se refere ao desenvolvimento de habilidades comunicacionais nos profissionais de saúde a partir da graduação.
\end{abstract}




\section{KEY-WORDS}

- Education, Medical.

- Problem Based Learning.

- Health Communication.

- Physician-Patient Relations.

- Humanization of Assistance.
ABSTRACT

Introduction: Communication presents itself as a skill that must be earned in medical graduation, being configured as a field of knowledge to be contemplated with regard to medical training. The way the communication is made, including its content, are important elements of the bond established between patient, health team, family and health institution. Considering the National Curricular Guidelines, learning is stimulated through active methodologies, with communication as part of the teaching-learning process, with the challenge of contemplating the communication of bad news in an effective way during formation. Objective: To analyze the perceptions of medical students studying an organized curriculum with active methodologies about the communication of bad news in medical formation. Method: This was a qualitative study, carried out at the School of Medicine of Marilia. Thirty-nine students from the $1^{\text {st }}$ to the $6^{\text {th }}$ years of the medical course participated in the study. Data collection was performed through a semi-structured interview and the data were analyzed using the Content Analysis technique, in the thematic modality. Results and discussion: Based on the analysis, four thematic categories were identified: Difficulty in defining bad news: product or process?; Is it possible to learn how to give or receive bad news from experience?; Difficulties in implementing an integrated curriculum: insufficient theoretical-practical articulation in bad news communication; and Valuing the communication of bad news: it takes theoretical, technical and emotional preparation. The results allow an important well-defined look at the perception of students about the communication of bad news within the curricular proposal. Final considerations: It is pointed out that the study participants perceive the need for greater theoretical-practical articulation, training of teachers and care regarding the personal and professional formation of students regarding what comprises the communication of bad news. We expect the study to contribute to the broadening the perspectives on the subject, regarding the development of communication skills in health professionals, since the undergraduate years.

Recebido em 1/6/19

Aceito em 22/7/19

\section{INTRODUÇÃO}

A comunicação se apresenta como uma habilidade que deve ser conquistada na graduação médica, configurando-se como um campo de conhecimento a ser contemplado no que se refere à formação médica ${ }^{1}$.

Os novos contornos e demandas da área de saúde do Brasil levam à necessidade de adequar as diretrizes curriculares ao curso de graduação em Medicina², promulgadas pela Resolução CNE/CES de 20 de junho de 2014, retomando-se a Política Nacional de Humanização $(\mathrm{PNH})^{3}$, que identifica o reconhecimento dos aspectos subjetivos nas relações interpessoais.

Um aspecto importante no que se refere à comunicação e que constitui uma das problemáticas para a relação interpessoal nos serviços de saúde é a comunicação de "más notícias". Neste contexto, entende-se como "má notícia" toda informação que envolva uma mudança drástica e negativa na vida da pessoa e na perspectiva do futuro ${ }^{4}$. Outra definição indica que é toda comunicação relacionada com o processo de atenção médica que traz uma ameaça ao estado mental ou físico do paciente e um risco de este ver superado seu estilo de vida já estabelecido $^{5}$

Assim, a maneira como a notícia é transmitida interfere diretamente na relação médico-paciente; no modo como o indivíduo lida com o diagnóstico, bem como na esperança desenvolvida após a notícia; nos relacionamentos pessoais e familiares; na busca por melhor qualidade de vida; e na adesão ao tratamento ${ }^{6}$.

A discussão sobre a importância da comunicação de más notícias teve início no século passado, quando a maioria dos médicos não comunicava o diagnóstico de câncer a seus pacientes. No início da década de 1960, um questionário foi aplicado a 219 médicos de uma cidade norte-americana e demonstrou que $90 \%$ deles não revelavam o diagnóstico de câncer aos seus pacientes ${ }^{7}$. Após vinte anos, o mesmo questionário foi aplicado a 699 médicos de hospitais universitários americanos e foi constatado que $97 \%$ deles afirmavam comunicar más 
noticias aos seus pacientes. Os motivos encontrados para esse resultado foram as iniciativas nas escolas médicas e os treinamentos intra-hospitalares ${ }^{8}$.

Embora a comunicação de más notícias seja comum e de evidente importância no contexto da relação médico-paciente e apesar de existirem na literatura instrumentos que ajudam a reduzir a ansiedade na comunicação de más notícias ${ }^{9,10}$, verifica-se que essa questão ainda não é devidamente tratada na formação médica no País e no mundo9,11.

Um recente estudo investigou a realidade sobre o ensino de habilidades de comunicação nas escolas médicas do Brasil. Entre 237 escolas existentes, 162 responderam ao questionário da pesquisa. Destas, $64 \%$ ofereciam treinamento formal de tal aptidão, especialmente nos anos pré-clínicos da graduação. $\mathrm{O}$ ensino dessa habilidade em situações especiais como a de más notícias foi reportado em apenas 41 instituições brasileiras, estando ausente na maioria das 18 matrizes curriculares ${ }^{12}$. Tais carências no ensino formal da comunicação de más notícias se refletem em um cenário no qual, por um lado, têm-se profissionais da saúde que não se sentem preparados para comunicar más notícias e, por isso, sofrem ao fazê-lo; e, por outro, tem-se a necessidade de comunicá-las como atividade quase diária da profissão ${ }^{13}$. Diante disso, estudos apontam que a maioria dos médicos refere utilizar sua experiência clínica para decidir como se comportar ao transmitir uma notícia difícil, uma vez que, enquanto estudantes, tiveram escassas oportunidades de aprofundamento nessa habilidade ${ }^{14}$.

O presente estudo parte de um currículo organizado em metodologias ativas com a comunicação como parte do processo ensino-aprendizagem, com o desafio de contemplar a comunicação de más notícias de forma efetiva na formação. Teve-se por objetivo analisar as percepções do estudante de Medicina acerca da comunicação de más notícias na formação, considerando a operacionalização do currículo organizado com metodologias ativas.

\section{METODOLOGIA}

\section{Desenho do estudo}

Trata-se de pesquisa qualitativa capaz de ampliar a compreensão do significado e da intencionalidade como inerentes aos atos, às relações e às estruturas sociais como construções humanas significativas ${ }^{15}$.

\section{Caracterização da situação de estudo}

Este estudo foi realizado numa instituição de ensino superior com estudantes do curso de Medicina, que tem estrutura curricular anual, seriada, em período integral, utilizando métodos ativos de ensino-aprendizagem ${ }^{16}$.
Da primeira à quarta série, apresentam-se a Unidade Educacional Sistematizada (UES), a Unidade de Prática Profissional (UPP) e o Laboratório de Prática Profissional (LPP). Para a quinta e sexta séries do curso, os cenários são apenas a UPP e a Unidade Educacional Eletiva (UEE) ${ }^{17}$.

Na UES, o estímulo à aprendizagem advém da representação da realidade por meio de um problema de papel, previamente elaborado pelas equipes de construção com base em situações reais vindas dos cenários de prática profissional ${ }^{17}$.

Desde o primeiro ano letivo, os estudantes iniciam atividades em cenário real da prática profissional, onde, nos dois anos iniciais, há a integração dos cursos de Medicina e Enfermagem no cenário da Estratégia Saúde da Família (ESF). O LPP traz situações simuladas, previamente estruturadas pelos docentes. O Apoio é o outro momento do LPP, realizado com a participação de um professor de Semiologia, que tem a função de explorar as prescrições obtidas com a prática ${ }^{16}$.

Na UPP, desenvolve-se o ciclo pedagógico com a Metodologia da Problematização, ao passo que a UES utiliza a metodologia da Aprendizagem Baseada em Problemas (ABP) ${ }^{17}$.

Na UEE, o estudante tem a oportunidade de participar ativamente da construção curricular, orientado por um docente, escolhendo seu local de preferência, optando por áreas de interesse de atuação, de fragilidade ou que requerem aprofundamento de conhecimento, além de desenvolver habilidades e atitudes ${ }^{17}$.

\section{Participantes e procedimentos de coleta de dados}

Participaram do estudo os alunos da primeira à sexta série do curso de Medicina, selecionados por meio de sorteio simples em cada série. Foram excluídos os estudantes transferidos de outras escolas. Procurou-se contemplar estudantes de todas as séries do curso para abrangência do estudo em relação à proposta curricular, contemplando, assim, maior diversidade de experiências.

A pesquisa foi constituída por nove participantes da primeira série, cinco da segunda série, cinco da terceira série, cinco da quarta série, dez da quinta série e cinco estudantes da sexta série, sendo o número de participantes finalizado pelo critério de saturação teórica ${ }^{18}$.

De modo geral, a predominância dos participantes da pesquisa foi do sexo feminino, e a média geral de idade foi de 23,9 anos.

Os dados foram coletados de agosto a dezembro de 2017, de forma individual, em local e horário agendados pela própria pesquisadora, por meio de entrevista semiestruturada, com perguntas norteadoras: (a) O que você entende por más notícias?; (b) Qual a sua experiência em dar ou receber más 
notícias?; (c) Quais foram as oportunidades de aprendizagem na graduação com relação à comunicação de más notícias?; (d) Qual a importância da comunicação de más notícias na sua formação profissional?

As entrevistas foram realizadas em locais que assegurassem o anonimato e o sigilo das informações e foram audiogravadas, tendo duração média de 11 minutos.

\section{Aspectos éticos}

O projeto foi encaminhado ao Comitê de Ética em Pesquisa (CEP) da Faculdade de Medicina de Marília, com o parecer consubstanciado $n^{\circ}$ 2.171.190, em cumprimento da Resolução 466/2012 do Conselho Nacional de Saúde ${ }^{19}$. Todos os participantes foram convidados por meio telefônico obtido por intermédio da secretaria acadêmica e receberam informações acerca do objetivo da pesquisa, das atividades desenvolvidas e de seus direitos.

Para orientar os participantes da pesquisa e obter sua permissão para colher os dados das entrevistas, foi-lhes apresentado o Termo de Consentimento Livre e Esclarecido (TCLE), que foi assinado para que o processo se iniciasse.

\section{Organização e análise de dados}

Com o intuito de preservar o anonimato dos participantes, os estudantes foram identificados com a letra "E", seguida das séries correspondentes, entre parênteses, ao final dos trechos das entrevistas, ilustrando a apresentação dos resultados (ex.: E1 - 1aㅗ série).

$\mathrm{Na}$ análise dos dados das entrevistas, foram considerados todos os depoimentos dos participantes, os conteúdos foram transcritos, e os dados foram tratados e relacionados entre si, sendo analisados pela técnica de Análise de Conteúdo, na modalidade temática ${ }^{15,20}$.

Para análise dos dados qualitativos, os depoimentos dos participantes foram transcritos, e os dados analisados. Elaborou-se um quadro para apresentar os diferentes núcleos de sentido presentes, organizados para buscar os temas (Quadro 1). A elaboração dos núcleos de sentido e a organização que emerge com base nos temas foram executadas por dois pesquisadores de forma independente, seguidas da validação conjunta do que foi classificado.

\section{RESULTADOS E DISCUSSÃO}

Dificuldades em definir "comunicação de más notícias": produto ou processo?

Observou-se, entre os entrevistados, na definição de más notícias, a compreensão de enfermidade grave, terminal, sem perspectivas de cura ou melhora, tendo a morte como desfecho, em geral.
[...] más noticias é isso de um paciente vir a falecer ou estar com uma doença terminal, uma doença muito grave. (E17 $3^{\text {a }}$ série)

[...] tem relação com [...] algum problema, alguma enfermidade, entendeu? [...] que não tem perspectiva de melhora, que não tem uma perspectiva de cura, ou então o óbito mesmo. (E2 - $1^{\underline{a}}$ série)

[...] informar geralmente o paciente sobre uma condição grave que ele tenha, uma doença grave que ele tenha, sobre possível evolução do quadro dele que seja o óbito mesmo. (E20 $-4^{\mathrm{a}}$ série)

Situações de debilidade, dependência, invalidez e perda de autonomia também foram mencionadas pelos participantes, que relacionaram essas situações com a comunicação de más notícias:

[...] qualquer coisa que diminua a qualidade de vida do paciente ou que faça com que ele perca sua autonomia de alguma maneira. (E23 - $4^{\mathrm{a}}$ série)

[...] comunicação de doenças de difícil resolução, ou incuráveis, ou que vão debilitar o paciente, que vão demandar um acamamento ou então uma dependência. (E8 - $1^{\mathrm{a}}$ série)

Um aspecto encontrado foi a ideia da má noticia como peso emocional e/ou social, que por si só gera um impacto, por ser da ordem do inesperado, não planejado, não benéfico, não agradável:

[...] qualquer notícia que vai causar um impacto forte no paciente pode ser alguma má noticia. (E18 - 3ª série)

[...] má noticia é aquela que ocorre fora... é o inesperado. (E30 $-5^{\mathrm{a}}$ série)

Uma ênfase se deu na relação entre alguém que comunica e alguém que recebe a notícia ou a informação. Sendo assim, é preciso preparo diante da reação, a fim de evitar maiores danos relacionados às suas repercussões.

[...] a comunicação em relação a patologias já entra como má notícia porque você não sabe como o paciente vai reagir em relação a isso. (E1 - $1^{\mathrm{a}}$ série)

[...] como você dá essa notícia para a pessoa não reagir de uma forma muito ruim. (E6 - $1^{\mathrm{a}}$ série) 


\section{QuAdro 1}

Núcleos de sentido e temas: "Comunicação de Más Notícias" (2018)

Temas

1. Dificuldades em definir "comunicação de más notícias": produto ou processo?

\section{Núcleos de sentido}

- Enfermidade grave, terminal, exemplificada pelo diagnóstico de câncer, sem perspectivas de cura ou melhora, tendo a morte, em geral, como desfecho.

- Repercussões como debilidade, dependência, invalidez e perda de autonomia, expressas como prejuízo funcional, agudo ou crônico, relacionadas ao diagnóstico e/ou tratamento.

- Peso emocional e/ou social, que por si só gera um impacto por ser da ordem do inesperado, não planejado, não benéfico, não agradável.

- Relação entre alguém que recebe e alguém que comunica (paciente e/ou família), merecendo preparo diante da reação, a fim de evitar maiores danos.

- Desconforto relacionado à quebra de expectativas da vida, com consequente frustração.

- A notícia e sua comunicação são dependentes do significado do profissional e do paciente.

- Má notícia como processo temporal, a curto e a longo prazo.

- Não reconhece experiência em dar e/ou receber más notícias.

Vivências pessoais

- Dar más notícias: experiências de quebra de expectativas e frustração não diretamente associadas a patologias.

- Receber más notícias: experiência pessoal e/ou familiar de doença, relacionada à comunicação de diagnóstico e/ou morte.

2. É possível aprender a dar ou receber más notícias pela experiência?

- O impacto ao receber a má notícia: ligação afetiva, expectativas, preparo ou forma de ser comunicado, incluindo o vínculo estabelecido com quem dá a notícia.

- As várias formas de receber más notícias.

Vivências da prática profissional

- Experiência nos primeiros anos: vivência da prática profissional no cenário simulado.

- Experiência no internato: observador desta prática ou com uma responsabilidade compartilhada pela informação do profissional ao paciente no cenário real.

- Necessidade de continência afetiva e preparo técnico.

- A experiência (positiva ou negativa) é vinculada ao modelo do profissional em comunicar más notícias.

- Não sendo oportunizada a teoria e a técnica de comunicação de más notícias.

- O disparador referente ao caso, ao cenário real ou simulado aborda indiretamente a técnica ou a comunicação de má notícia.

3. Dificuldades na implementação do currículo integrado: insuficiente articulação teórico-prática em comunicação de más notícias

- Disparado por uma necessidade dos estudantes ou dependente do professor e não por intencionalidade ou por sistematização curricular. Não é uma constante entre os grupos.

- Contato superficial nos cenários de tutoria, reais e simulados até a quarta série.

- Maior aproximação prática no internato ou no cenário eletivo. Aprendizado por observação. Modelo do professor. Depende da sensibilidade do professor. Oportunidade do dia a dia, na prática. Muitas vezes, realizado sem preparo prévio.

- Buscando a técnica em atividades extracurriculares.

4. Valorizando a comunicação de más notícias: é preciso preparo teórico, técnico e emocional
- A comunicação de más notícias faz parte da prática médica, independentemente da área a ser seguida.

- Necessidade de preparo teórico, técnico e emocional para comunicação de más notícias.

- Aprendendo com outros profissionais: o papel do profissional de saúde mental na comunicação e no trabalho em equipe.

- O caráter implícito e transversal da humanização das práticas.
Algumas entrevistas demonstram a compreensão da má notícia como algo validado como "boa" ou "má", segundo a percepção dos próprios pacientes.

[...] às vezes, o que é má notícia para um não é para outro. (E2 - $1^{\mathrm{a}}$ série)

\section{[...] é qualquer notícia que vai passar um desconforto para o} paciente, não necessariamente uma coisa muito trágica assim... até porque o que é trágico para você pode não ser para ele e vice-versa. (E7 - $1^{\mathrm{a}}$ série)

E a ideia de processo, ilustrada por sua temporalidade, a curto e a longo prazo:
[...] a gente tem muito essa ideia da cura, que a cura é o final feliz para uma consulta [...] se eu falar: "você tem uma doença que vai demandar um tratamento contínuo", para mim isso já começa sendo uma má noticia [...] começa desde um aspecto um pouco, não menor, mas mais restrito e vai até esse último que seria o mais trágico, digamos assim. (E22 - $4^{\mathrm{a}}$ série)

Segundo Pereira4, as "más notícias" em saúde incluem situações que constituem uma ameaça à vida e ao bem-estar pessoal, familiar e social, pelas repercussões físicas, sociais e emocionais que acarretam.

Entendida como uma situação que gera perturbação, quer na pessoa que recebe a notícia, quer na pessoa que a transmite, a comunicação deste tipo de notícia torna-se tarefa difícil para 
todos os profissionais de saúde não só pelo receio de enfrentar as reações emocionais e físicas do doente ou dos familiares, que também sofrem o abalo ou impacto da notícia, como também pela dificuldade de gerir a situação ${ }^{4}$.

Mori e Rey ${ }^{21}$ comentam sobre a subjetividade e o processo de adoecimento, e afirmam que "os processos subjetivos envolvidos nessa experiência se organizam de maneira diferenciada não apenas pelo momento atual da pessoa, mas também pelas diferentes representações, crenças e emoções que se organizaram em outras áreas da sua vida e se articulam com o momento do adoecimento em processos de sentido subjetivo que modificam ou não as configurações subjetivas da pessoa".

De forma geral, as dificuldades apareceram atreladas à forma de qualificar a má notícia enquanto produto "ruim", com ênfase no processo de comunicação, mobilizado pela forma interacional e intersubjetiva.

A compreensão de más notícias não foi heterogênea em relação às séries de graduação e, assim, não classificada com graus crescentes de compreensão e maior domínio de seu conteúdo. Isto pode ser visto pelas diferentes apreensões dadas à má notícia e sua comunicação, que não foram divergentes em relação às séries, mas em relação às experiências dos estudantes entre si.

\section{É possível aprender a dar ou receber más notícias pela experiência?}

Quando solicitado aos estudantes que apontassem qual(is) tinha(m) sido sua(s) experiência(s) em dar ou receber más notícias, pôde-se notar a diferença da vivência em relação ao período de graduação.

A experiência de dar más notícias foi classificada por dois estudantes como ter que passar a alguém de valor uma notícia que seria delicada, não necessariamente relacionada à saúde, mas com quebra de expectativas e frustração para ambos, de forma mais ampla:

[...] dar más notícias assim, na vida, [...] já tive que falar para minha mãe que eu não passei no vestibular, que era uma má notícia para mim e para ela. (E2 - 1ª série)

[...] já tive que falar para o meu irmão que ele não ia ser atleta e foi muito difícil isso. Que ele não passou e eu passei na faculdade também. (E10 - 2ª série)

Receber más notícias foi classificado como experiência pessoal e/ou familiar de doença, relacionada à comunicação de diagnóstico e/ou morte. O impacto ao receber a má notícia é qualificado pela ligação afetiva e pelas expectativas, conside- rando-se o processo de adoecimento ou ocorrência e o preparo ou forma de ser comunicada, incluindo o vínculo estabelecido com quem dá a notícia, seja parente ou profissional.

[...] pessoalmente, eu já recebi má noticia, tive um diagnóstico de câncer de tireoide [...] (E29 - 5ª série)

Então, nas duas vezes foi a minha mãe que me deu a notícia, $e$ eu estava dormindo [...] fui acordada com essa notícia, dessa maneira: "a vó faleceu, levanta que a vó faleceu e a gente está indo" e depois: "levanta, o vô faleceu, e a gente está indo"... $e$, assim, a minha avó infartou, então foi bem inesperado, e o

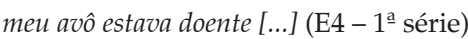

[...] receber eu já recebi de formas muito boas, em que a pessoa sentou comigo, me acolheu [...] explicou a situação... foi explicando todo o processo do que aconteceu [...] até chegar na má notícia e eu já recebi também a bomba da pessoa nem me dar um oi direito e já mandar a bomba logo direto e eu ficar completamente sem reação também. (E11 - 2ª série)

A experiência em dar más notícias como prática profissional foi identificada nos primeiros anos mais vinculada ou vivenciada no cenário simulado:

[...] dar más notícias no LPP no caso de comunicação dolorosa fui eu que tive que entrevistar o paciente [...] no caso, ele falou que já tinha pego dengue duas vezes e me perguntou: "É verdade que o risco é maior? É verdade que pode dar mais complicações?" e eu não sabia como responder [...] senti preocupação, mais preocupação do que qualquer outra coisa; dependendo do jeito como eu vou falar com o paciente, ele pode reagir de uma forma horrível ou pode aceitar. (E6 - 1aㅗ série)

O cenário simulado oferece a oportunidade de experimentar e aprender em um ambiente seguro, sem a possibilidade de prejudicar pacientes reais. Nesses espaços, as simulações podem ser padronizadas, com reprodução dos mesmos papéis específicos para todos os estudantes, improvisadas ou personalizadas de acordo com a dificuldade individual, possibilitando, ainda, refazer uma situação de dificuldade ${ }^{6,22}$.

No cenário real, identificam-se experiências no internato em que um estudante ilustra a responsabilidade compartilhada pela informação do profissional ao paciente:

[...] dar más notícias acho que foi mais no internato mesmo que eu tive essa experiência de ter que compartilhar junto com os médicos e residentes um pouco dessa responsabilidade 
de falar para os familiares ou até mesmo para os pacientes. (E38 - 6 $6^{\mathrm{a}}$ série $)$

É percebido o (des)preparo do profissional/professor, e a experiência (positiva ou negativa) é vinculada ao modelo do profissional para comunicar más notícias.

[...] às vezes, a gente vê um professor dando uma notícia e acaba pensando: "isso foi legal"... essa forma como ele falou, ou a forma como ele agiu, o que ele fez... você acaba pegando coisas boas ou até coisas ruins, do tipo isso não foi legal, eu não faria assim; então, você tem o exemplo de como ser e o exemplo do que não fazer também... acho que se você conseguir filtrar isso, você consegue ter uma forma de lidar com isso muito bem. (E30 - 5 ${ }^{\text {a }}$ série)

Considerações de dois estudantes trazem a percepção da singularidade do preparo do oncologista e dos profissionais que lidam com cuidados paliativos, por vivenciarem mais estas situações, especialmente por haver uma equipe multiprofissional envolvida que auxilia e prepara o médico para dar más notícias.

[...] os médicos oncologistas [...] a gente percebe que eles se interessam e estão mais prontificados a ajudar diante dessas situações. Acho que muito mais por um costume que eles têm de lidar com isso e ter uma equipe multiprofissional muito bem envolvida também, com psicólogos, psiquiatras e tantas outras pessoas que auxiliam esses médicos e formam esse médico para dar essas notícias. (E12 - 2ª́ série)

[...] nos cuidados paliativos, eu já vi uma coisa superdiferente. [...] juntamos toda a equipe, nutricionista, físio, todas as pessoas que faziam parte da equipe de paliativos, sentamos junto com os pais da criança, e a médica perguntava o que eles sabiam do paciente: "o que você sabe que seu filho tem, o que você acha que ele tem"; perguntava as expectativas que eles tinham, que ela vinha carregando [...] e aí, a partir desses dados que a médica ia tendo, ela sabia como ia ter que abordar; e era muito incrível, todo mundo da equipe junto, gente, isso é receber notícia! (E18 - 3aㅗ série)

No contexto em que se encontra o maior problema na relação, a fragilidade do outro mostra ao médico a própria fragilidade, e a finitude do paciente faz o médico pensar em sua própria finitude, o que, por sua vez, gera sofrimento. Para evitá-lo, para aliviar angústias, reduzir tensões e amenizar sentimentos, mecanismos de defesa são ativados, muitas vezes não permitindo o manejo adequado das questões emocionais ${ }^{14}$.
Neste sentido, Gomes e Othero ${ }^{23}$ afirmam que os Cuidados Paliativos se apresentam como uma forma inovadora de assistência, pois abordam o ser humano em sua integralidade e se apresentam com o diferencial do suporte da equipe multiprofissional: "a necessidade de intervenção em sintomas de natureza física, social, emocional e espiritual transforma a prática dos Cuidados Paliativos em um trabalho necessariamente de equipe, de caráter multiprofissional e interdisciplinar".

Dificuldades na implementação do currículo integrado: insuficiente articulação teórico-prática em comunicação de más notícias

Com relação às oportunidades de aprendizagem, os estudantes, independentemente da série, identificam que a teoria e a técnica de comunicação de más notícias não foram abordadas no currículo. Considerando que as séries iniciais podem ainda não ter esta apropriação da oportunidade curricular, não conseguem identificar momentos sistematizados, o que também chamam de formal no currículo:

Na graduação eu não tive não. Todos os problemas que a gente teve, que a gente viu nas tutorias, nenhum abordou a comunicação de más notícias. (E3 - 1ª série)

[...] durante a graduação eu não tive contato pela faculdade... [...] um momento específico na tutoria, um momento específico na UPP, de pegar ali um artigo sobre o assunto. (E17 - $3^{\text {a }}$ série)

Nenhuma. [...] algo mais formal não tivemos, não. Nem em $U P P$, nos LPPS, nem nas tutorias, algo formal, não. (E18 - $3^{\text {a }}$ série)

Percebe-se uma necessidade de, para além da teoria, compreender a técnica de comunicar más notícias, articulando a necessidade do fazer ou da abordagem propriamente dita.

A gente tem nas tutorias do primeiro ao quarto ano um pouco de coisa, mas é uma coisa mais abstrata, mais teórica, mais de estudar o processo de luto... a gente estuda as fases do luto, mas ter uma técnica de comunicação, de conversar, assim, não... (E39 - 6 $6^{\mathrm{a}}$ série)

A falta, então, parece se atrelar ao desejo predominante do "como fazer", nem sempre previsto em todas as situações em virtude do caráter dinâmico em que as vivências se colocam.

Quando identificam alguma oportunidade, o disparador referente ao caso de tutoria, ao cenário real ou simulado abor- 
da indiretamente, em sua perspectiva, a técnica ou a comunicação de más notícias:

O que a gente estudou foi a empatia, foi a questão profissional de saúde-paciente, isso aí a gente viu, o que acaba envolvendo um pouco essa questão de dar a má notícia, mas especificamente a má notícia, não. (E27 - 5ª série)

Ou as oportunidades se vinculam a valorizações isoladas de tutores, facilitadores e estudantes para disparar a discussão:

[...] na tutoria a gente já tinha aberto questões em um dos anos anteriores, mas é desse jeito que eu te falei, a gente abre as questões e quem está à vontade estuda, quem não... e aí a discussão da questão acaba sendo bem rápida. (E25-5ª série)

E ai vai muito do momento também; se o assistente que está lá, se o residente quiser discutir sobre isso com você, mas nada sistematizado. (E38 - 6 $6^{\mathrm{a}}$ série)

A primeira aproximação que eu tive foi durante um dos casos de tutoria que uma aluna tinha visto no grupo de UPP dela e achou que era pertinente a gente estudar comunicação de más notícias porque a paciente acabou falecendo no caso [...] (E13 - 2ª série)

Os contatos nas séries iniciais são descritos ainda com maior distanciamento prático. Na prática (UPP), os alunos referem não acompanhar o processo de diagnóstico, de comunicação da notícia. Têm contato teórico com a comunicação de más notícias, mas nada no contexto prático no sentido de fazer num espaço em que o manejo pudesse ser avaliado.

\section{[...] é um pouco desconexo porque a gente começa na prática desde o primeiro ano, mas a gente começa nos postos de saúde e a gente não lida muito com isso. A gente pega muito pacien- te sem queixa específica, muito paciente portador de doença crônica, diabetes, hipertensão, então a gente acaba não levan- do isso muito pra frente. Terceiro ano também não vê muito, quarto ano é mais ambulatorial, aí vai ter esse contato mesmo no quinto e sexto ano, que é no internato. (E39 - 6⿳a série)}

A maior aproximação com a prática da comunicação é descrita no cenário hospitalar, no internato ou no eletivo. Porém, o predomínio é de observação da prática, seguindo-se a aprendizagem com o modelo do professor, dependente de sua abordagem e atitude, o que, muitas vezes, é realizado sem preparo prévio.
[...] a partir do quinto ano a prática é bem maior, mas não é nada sistematizado com um professor que fala: "vamos juntos que eu quero ver você falando essa má notícia", então isso não tem. A gente vai fazendo de acordo com o que a gente vai observando, acaba entrando por osmose mesmo assim. (E35 $-6^{\mathrm{a}}$ série)

Para o estudante, a forma como é tratado pelo professor é um dos primeiros processos de aprender a se relacionar.

[...] eu não tinha experiência prática nenhuma, mas a gente tinha um professor muito bom, muito humano. Então, ele chegava e dizia: "A gente tem que falar, conversar com o acompanhante do paciente que ele tem poucas chances, que ele está com uma neoplasia, que é grave, que deu metástase. Você se sente confortável para isso?" "Ainda não, professor". "Então vamos lá, que eu vou conversar junto!" (E30 - 5a série)

Muitos participantes se recordam, desde as séries iniciais, de simpósios e outras atividades extracurriculares, organizadas por Ligas Acadêmicas, que buscaram abordar esse tema pela falta sentida da teoria e da técnica em comunicar más notícias no currículo:

[...] na verdade, partiu de mim... teve uma jornada, se não me engano foi de Clínica Médica, esse ano, e um dos temas era comunicação de más noticias. Para mim, aquilo foi fantástico porque até então, que eu me lembre, não tive nada assim, de específico, na faculdade, falando sobre isso. (E14 - 2ª série)

Questiona-se se a busca por Ligas Acadêmicas e por atividades do currículo paralelo, por se entender que se trata de uma tentativa de complementar conteúdos dos currículos em função da insegurança dos estudantes. Quando entendidas no contexto de currículo paralelo, com prejuízo e subversão da estrutura curricular formal, as Ligas Acadêmicas passam a ser criticadas pelo risco adicional à formação médica quando reproduzem vícios acadêmicos e se tornam um espaço para especialização precoce ${ }^{24}$.

A maneira como o professor ensina e se relaciona com os estudantes é considerada, por si só, um modo de formação, uma vez que o tipo de interação entre professor e estudante influencia o aprendizado. Deste modo, destaca-se a importância da construção e do exercício de relações de parceria ${ }^{22}$.

É importante que todos os formadores tenham a oportunidade de aperfeiçoamento nas habilidades de comunicação para que possam facilitar a aprendizagem. É necessário tam- 
bém criar programas de desenvolvimento para preparar os docentes para o ensino-aprendizado das habilidades de comunicação em todos os níveis de formação, sensibilizar diretores de programas e administradores acerca da importância de desenvolver excelentes programas de comunicação em suas instituições e aumentar a formação de facilitadores e professores neste tema tão importante para a formação de bons médicos ${ }^{22}$.

Valorizando a comunicação de más notícias: é preciso preparo teórico, técnico e emocional

O relato de uma participante procura ilustrar que, na prática profissional, seja qual for a especialidade, esta abordagem sempre será necessária:

[...] é essencial porque a gente lida com isso o tempo todo, todos os dias, infelizmente, eu dou mínimas más notícias para alguém [...] todos os dias a gente lida com muitas frustrações, e a gente acaba tendo que... a gente é muito porta-voz de más notícias. (E26 - 5ª série)

Os estudantes apontam a necessidade de preparo teórico, técnico e emocional durante a graduação, uma vez que as fragilidades identificadas se associam a saber dar a notícia e a saber lidar com a notícia:

[...] eu acho que é bom abordar durante a graduação toda, porque do mesmo jeito que eu tive bons exemplos de residentes, médicos, passando essas más notícias, eu também tive péssimos exemplos [...] o médico vai lá e fala: "morreu" e dane-se a família [...] é importante para saber conduzir (E38 - 6 é $^{\mathrm{a}}$ érie)

[...] é uma coisa que mexe muito com a gente, com [...] até a nossa saúde mental [...] importante saber fazer e como fazer até porque abala quem a gente é... não é só o paciente. (E6 $1^{\mathrm{a}}$ série)

Também são comentadas as possibilidades de explorar mais a comunicação na presença do profissional de saúde mental e a potência do trabalho em equipe enquanto formador, considerando práticas interprofissionais, compartilhadas e de apoio:

[...] a gente tem na parte prática atividades junto com psicólogos, mas acho que ainda falta um pouco mais, principalmente para esse lado de comunicação, de entender, de conseguir se colocar mais no lugar do paciente, porque, quando você recebe, você percebe o quanto é difícil lidar com isso. (E30 - 5 ${ }^{\mathrm{a}}$ série $)$
[...] ou um trabalho com a equipe multidisciplinar [...] a gente acaba recorrendo muito aos outros profissionais. "Vamos chamar a psicologia, vamos chamar a assistente social para conversar junto" porque a gente não sabe fazer isso [...] e a gente vai meio que atrás da pessoa para ver o que ela vai fazer por mim. Eu acho que isso deveria ser trabalhado de uma forma mais conjunta porque hoje está muito separado. (E26 - 5ª série)

Os entrevistados apontam o caráter implícito e transversal da humanização das práticas, que vai além da profissão, e que a comunicação com o paciente é a parte mais importante de qualquer processo de saúde que envolva o cuidado em dar ou receber más notícias.

[...] eu acho que vai além da sua profissão, isso é uma coisa mais humana. (E7 - $1^{\underline{a}}$ série)

[...] acho que a comunicação com o paciente é a parte mais importante de qualquer processo de saúde. Independente se você sabe conduta, se você sabe medicar, estabelecer vínculo, ter uma comunicação aberta, transparente, honesta, sincera, acho que é a melhor maneira de você trabalhar boas e más notícias. (E31 - 5ª série)

É necessário resgatar a importância de refletir sobre a relação médico-familiar como uma prática diária tão relevante quantos outros ensinamentos da medicina - uma prática que envolva tanto um aparato teórico, que instrumentalize e auxilie na resolução de problemas, quanto um aparato que lide com sentimentos e emoções dos futuros médicos. Deste modo, além do preparo relacionado a uma base científica, é de suma importância a possibilidade de refletir sobre os seus sentimentos frente à doença e à morte 9 .

\section{CONSIDERAÇÕES FINAIS}

Os resultados que emergiram deste estudo trazem a importância de investigar formas de esta temática ser mais bem significada e apreendida pelos estudantes, uma vez que estes ainda solicitam algo específico dentro do que se pode trabalhar em termos de referencial de comunicação.

No currículo organizado com metodologias ativas, aponta-se a necessidade de maior articulação teórico-prática, preparo dos docentes e um cuidado com a formação pessoal e profissional dos estudantes.

Enquanto limitação do estudo, considerando-se o trabalho em um currículo integrado, seria importante fazer a escuta também de professores e gestores, participantes dos proces- 
sos de construção e avaliação curricular. Seria relevante também analisar os casos utilizados no espaço de simulação no LPP para melhor avaliar as oportunidades de aprendizagem no que se refere à aquisição de habilidades comunicacionais quanto à temática de comunicação de más notícias, considerando que este espaço conta, especificamente, com o auxílio de um professor da comunicação.

Estudos futuros podem investigar e intervir na realidade do ensino e do serviço com a proposição de maior articulação entre a teoria e a prática e a formação permanente de docentes/profissionais, com repercussões no cuidado em saúde.

\section{REFERÊNCIAS}

1. Rossi PS, Batista NA. O ensino da comunicação na graduação em medicina: uma abordagem. Interface (Botucatu) [Internet]. 2006 [citado 27 mar 2017];10(19):93-102. Disponível em: http://www.scielo.br/pdf/icse/v10n19/ a07v1019.pdf

2. Brasil. Ministério da Educação, Conselho Nacional de Educação, Câmara de Educação Superior. Resolução n. 3, de 20 de junho de 2014. Institui diretrizes curriculares nacionais do curso de graduação em medicina e dá outras providências. Diário Oficial da União, Brasília (DF); 23 jun 2014; Seção 1:8-11.

3. Brasil. Ministério da Saúde. Política Nacional de Humanização - HumanizaSUS [Internet]. Brasília (DF): Ministério da Saúde; 2017. [citado 14 jun 2018]. Disponível em: http://portalms.saude.gov.br/artigos/693-acoes-e-programas/40038-humanizasus

4. Pereira MAG. Má notícia em saúde: um olhar sobre as representações dos profissionais de saúde e cidadãos. Texto Contexto Enferm [Internet]. 2005 [citado 30 mar 2016];14(1):33-7. Disponível em: http://www.scielo.br/ pdf/tce/v14n1/a04v14n1.pdf

5. Muñoz JJA, Holland JC. La comunicación de las malas noticias en la relación médico paciente. III. Guía clínica práctica basada en evidencia. RevSanid Mil. 1999; 53(3): 220-224.

6. Sombra Neto LL, Silva VLL, Lima CDC, Moura HTM, Gonçalves ALM, Pires APB, et al. Habilidade de comunicação da má notícia: o estudante de medicina está preparado?.RevBrasEduc Méd. [Internet] 2017 [citado 09 jul 2018];41(2):260-8. Disponível em: http://www.scielo.br/ pdf/rbem/v41n2/1981-5271-rbem-41-2-0260.pdf

7. Oken D. What to tell cancer patients: a study of medical attitudes. JAMA. 1961; 175(13): 1120-1128.

8. Novack DH, Plumer R, Smith RL, Ochitill H, Morrow GR, Bennett JM. Changes in Physicians' Attitudes Toward Telling the Cancer Patient. JAMA. 1979; 241(9): 897-900.
9. Ostermann AC, Frezza M. "Veio o resultado do exame": a comunicação de notícias diagnósticas (e como investigações linguístico-interacionais podem informar as práticas profissionais). Ling (Dis)curso. [Internet] 2017 [ciatdo 09 jul 2018];17(1):25-50. Disponível em: http://www.scielo. br/pdf/ld/v17n1/1518-7632-ld-17-01-00025.pdf

10. Buckman R. Communication skills in palliative care. NeurologicClinics. 2001; 19(4): 989-1004.

11. Kiluk JV, Dessureault S, Quinn G. Teaching medical students how to break bad news with standardized patients. J Cancer Educ. 2012; 27(2): 277- 280.

12. Liberali R, Novack D, Duke P, Grosseman S. Communication skills teaching in Brazilian medical schools: whatlessonscanbelearned? PatientEducCouns. (2018). Disponível em: https:/ / doi.org/10.1016/j.pec.2017.12.021

13. Monteiro DT, Quintana AM. A comunicação de más notícias na UTI: perspectiva dos médicos. Psic.: Teor. e Pesq. [Internet] 2016 [citado 21 jun 2018];32(4):1-9. Disponível em: http://www.scielo.br/pdf/ptp/v32n4/1806-3446ptp-32-04-e324221.pdf

14. Rosenbaum ME, Ferguson KJ, Lobas JG. Teaching medical students and residents skills for delivering bad news: review of strategies. Acad Med. 2004;79(2): 107-117.

15. Minayo MCS. O desafio do conhecimento: pesquisa qualitativa em saúde. 13a. ed. São Paulo (SP): Hucitec; 2013.

16. Faculdade de Medicina de Marília. Caderno de avaliação: cursos de medicina e enfermagem [Internet]. Marília (SP): Faculdade de Medicina de Marília; 2015. [citado 4 jan 2017]. Disponível em: <http://www.famema.br/institucional/avaliacao/avaliacao.php

17. Faculdade de Medicina de Marília. Projeto Pedagógico do Curso de Medicina [Internet]. Marília (SP): Famema; 2014 [citado 12 abr 2018]. Disponível em: http:/ / www.famema. br/ensino/cursos/docs/PPC\%20Medicina.pdf

18. Turato ER. Tratado de metodologia da pesquisa clínico-qualitativa: construção epistemológica, discussão comparada e aplicação nas áreas de saúde e humanas. 6a. ed. Petrópolis (RJ): Vozes; 2013.

19. Brasil. Ministério da Saúde, Conselho Nacional da Saúde. Resolução no 466, de 12 de dezembro de 2012. Aprova as diretrizes e normas regulamentadoras de pesquisas envolvendo seres humanos [Internet]. Diário Oficial da União, Brasília (DF); 13 jun 2013; Seção 1:59. [citado 23 jun 2017]. Disponível em: http:/ /bvsms.saude.gov.br/bvs/saudelegis/cns/2013/res0466_12_12_2012

20. Bardin L. Análise de conteúdo. São Paulo (SP): Edições 70; 2012. 
21. Mori VD, Rey FG. A saúde como processo subjetivo: uma reflexão necessária. Psicol teor prát. 2012;14(3):140-52.

22. Dohms M, Tesser CD, Grosseman S. Potencialidades no ensino-aprendizagem da comunicação médico-paciente em três escolas brasileira, espanhola e holandesa. RevBrasEducMéd. [Internet] 2013 [citado 21 jun 2018];37(3):3119. Disponível em: http://www.scielo.br/pdf/rbem/ v37n3/02.pdf

23. Gomes ALZ, Othero MB. Cuidados paliativos. EstudAv. [Internet] 2016 [citado 09 jul 2018];30(88):155-66. Disponível em: http://www.scielo.br/pdf/ea/v30n88/01034014-ea-30-88-0155.pdf

24. Hamamoto Filho PT. Ligas acadêmicas: motivações e críticas a propósito de um repensar necessário. RevBrasEducMéd.[Internet] 2011 [citado 09 jul 2018];35(4):535-43. Disponível em: http://www.scielo.br/pdf/rbem/v35n4/ a13v35n4.pdf

\section{CONTRIBUIÇÃO DOS AUTORES}

Todos contribuíram integralmente e igualmente na realização do manuscrito.

\section{CONFLITO DE INTERESSES}

Não há.

\section{ENDEREÇO PARA CORRESPONDÊNCIA}

Faculdade de Medicina de Marília

Avenida José de Grande, 332 Jardim Parati

CEP 17519-030

Marília SP

Brasil. 